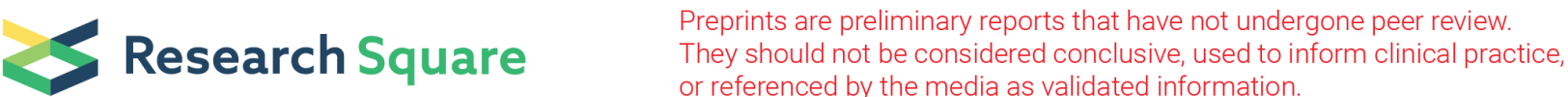

\section{Solidarity and Suffering: Patients and their Caregiver's Experiences Enrolled in the Community- Based Palliative Care Program in an Urban Slum of Bangladesh}

Sayema Akter ( $\nabla$ moonsayema@gmail.com )

BRAC University James P Grant School of Public Health

Malabika Sarker

BRAC University James P Grant School of Public Health

Puspita Hossain

BRAC University James P Grant School of Public Health

Nezamuddin Ahmad

Bangabandhu Sheikh Mujib Medical University

Shahaduz Zaman

Brighton and Sussex Medical School

Research article

Keywords: Bangladesh, Care-givers, Experience, Palliative Care, Terminal illness

Posted Date: August 18th, 2020

DOI: https://doi.org/10.21203/rs.3.rs-53343/v1

License: (c) (i) This work is licensed under a Creative Commons Attribution 4.0 International License.

Read Full License 


\section{Abstract}

Background: Palliative care has been recognized as a global health challenge. Although access has increased, there is very low recognition of the importance of palliative care in low and middle-income countries. In Bangladesh, institutional palliative care is not accessible due to a lack of awareness, financial constraints, and fewer facilities. Hence, there needs to be a better understanding of how to provide and improve existing community-based palliative care. This study aimed to explore the experiences of palliative patients and their primary caregivers enrolled in the palliative care project "Momotamoy Korail" run by Bangabandhu Sheikh Mujib Medical University in an urban slum of Dhaka.

Methods: A focused ethnography was conducted where observation and nineteen in-depth interviews were carried out using semi-structured guidelines with the palliative care patients and their primary caregivers.

Results: In a family, mostly wives and daughters-in-law are the primary caregivers. Therefore, male patients are more likely to receive family care compared to female patients. Both male and female patients expressed the desire for death free of suffering. All patients shared their feelings of loneliness and social abandonment, accentuated by the guilt of being a burden to their families, created a feeling of social death. Despite the sense of duty, sympathy and empathy, presence of the physical, social, psychological, and spiritual suffering, both patients and caregivers felt cared and hopeful.

Conclusion: There is a need for innovative approaches for an integrated palliative care service within the main stream health system. Gaps in research, workforce shortages, and lack in public and professional knowledge need to be addressed if care for people with a terminal illness and their silent savior is to be further improved.

\section{Background}

Focus on the conditions of death across the globe, and interest in the development of end of life care in the global context is growing $(1-3)$. It includes variation in different cultures and resource settings, the scope for health and social care services, the contribution of families and communities, and the role of civil society and organizations. The literature revealed how palliative care started as a social movement. It has become a medical specialty in the west, and over time expanded its scope, moving beyond the clinical domain (4). It has been recognised that although death happens to individuals, it is nevertheless a population experience, and as a result, palliative care should be considered a public health issue (5-7). Palliative care availability and access has also been acknowledged as a human right in recent years (1). However, as with other issues within health and health care, the issues around death, dying and palliative care in developing countries are characterised by enormous inequity. Very little is known about how the end of life is dealt with in low-income countries. A review showed that ninety percent of the studies on end of life care focus on just a few specific European countries (8). According to the global mapping on the level of palliative care, low and middle-income countries have a wide range of variation against the 
high-income countries on the readiness of their health systems for palliative care. (9). Given the total number of people requiring palliative care worldwide, only $10 \%$ of them receive the care they need as very few countries have integrated it into their healthcare systems (10).

The Lancet Commission on "Alleviating the access abyss in palliative care and pain relief" identified 20 most common health conditions that requires palliative care. Among these, the top 10 conditions account for more than ninety percent of deaths in low- and middle-income countries (LMICs). Palliative care would have been beneficial for almost $78 \%$ of the adults from LMICs. The provision of support varies from home-based palliative care to isolated clinical care to integrated palliative care offered within mainstream health services. In the vast majority of LMICs there is no institutional palliative care, and there is limited or no recognition of palliative care in health policy and a scarcity of specially trained human resources (1113). Authors argued that despite the fact that dying is a universal human experience more array is required about how it should be addressed (14).

In the current map of world palliative care, Bangladesh is in category 3a, that indicates the existence of isolated palliative care services and training provision (9). A recent situation analysis in Bangladesh reported that, even though Bangladesh has approximately 600,000 incurable patients, only a handful of centres provide palliative care and Bangabandhu Sheikh Mujib Medical University (BSMMU) is one of them(15). In urban slums, the impact of life-limiting conditions becomes devastating for family and community members due to poverty. Given the situation, the Centre for Palliative Care (CPC) of BSMMU undertook a pilot project called "Momotamoy Korail (Compassionate Korail)" in 2015 in an urban slum of Dhaka to provide care to the palliative and geriatric population at their homes. Twelve Palliative Care Assistants (PCAs) were recruited from the community and trained to provide care and treatment support to patients and their caregivers. The services included clinical examination and treatment, physiotherapy, home visit, and emergency physical care. Palliative Care Assistants (PCA) offer home-based palliative care services comprised of physical, social, psychological and spiritual care. They monitor the patient, provide information, needful physical care and bereavement support to the families when needed.

Alleviation from diverse suffering is a vital concern of palliative care services, and therefore it is necessary to identify the plight of the patient for providing quality palliative care based on the patients' needs (16). Patient experience is widely recognized as a pillar of quality in healthcare service due to its intrinsic value (17). Another essential aspect of palliative care is the support of primary caregivers, usually close family members. The primary caregivers provide care with no financial interest and often hamper their social lives (18). The demographics of the population change, and patients' preference to die in their own homes (19) is leading to a shift in caregiving responsibilities from more traditional medical personnel to spouses, family, and friends. Family caregivers are crucial for providing the majority of physical and emotional care for individuals with life-threatening and terminal illnesses, especially those who wish to die at home (20). Family caregiving comes with its own unique challenges and problems(21). In 2006, family caregiving was identified as a top international research priority in end of life care. Hence the effects of taking care of the dying patient, needs to be considered for providing a 
holistic care. Globally, there are very few examples of community-oriented end of life care in resourcepoor settings.

Among the 160 million inhabitants of Bangladesh, it is estimated that more than two million people are currently living in slums in the city of Dhaka. The Centre for Palliative Care (CPC), in collaboration with the Worldwide Hospice Palliative Care Alliance (WHPCA), piloted a project on homecare outreach palliative care service in a slum setting in Dhaka, Bangladesh. In this regard, a qualitative research approach can contribute to understand the complexity and contextual embeddedness of family caregiving experiences. It can also assist in developing empirical-based conceptual and theoretical frameworks for research and practice (22). Very few studies have reported on the ultimate experience, sufferings and issues of caregivers who care for people in need of palliative care in Bangladesh. The crucial role of the family members in the hospital settings in Bangladesh has been well explored by Zaman,(23) but until now no study has been done at the household settings. Given this context, we explore the experiences of the terminally ill patients enrolled in the community-based palliative care project and their caregivers living in an urban slum of Dhaka, Bangladesh.

\section{Methods}

\section{Study design}

This qualitative study relied on focused ethnographic approach. A focused ethnography generally focuses on a distinct problem in a specific context and is conducted within a sub-cultural group rather than with a cultural group (24).

\section{Study site and sample selection}

The study site was an urban slum named 'Korail' which is one of the largest slums situated in Dhaka Bangladesh(25). Participants were conveniently and purposively selected from the palliative care project run by BSMMU named "Momotamoy Korail". A list of patients with diagnosis was collected from the project staff. Both male and female patients with the most common five (cancer, stroke, multiple bony pain, respiratory tract infection, chronic kidney disease) types of ailments were selected and total ten patients and nine of their caregivers were interviewed. The researcher could not reach one of the caregivers due to her unavailability during the data collection period.

\section{Data collection}

After receiving the approval from the Institutional Review Board from both BRAC University and University of Sussex, two anthropologists were hired as local Research Assistants (RAs) and trained by the local Principal Investigator to conduct the focused ethnography. This focused ethnography was directly supervised and led by two other experienced qualitative researchers; one was a certified medical doctor and the other one was an anthropologist by training. The duration of the focused ethnography was two months and it involved observations and informal discussions as well as in-depth interviews and focus group discussions. 
Participant observation was done regarding the surroundings, experience of the patients, and caregiving process. Nineteen (19) semi-structured in-depth interviews (IDIs) with palliative care patients and their primary caregivers were conducted. Interviews were conducted in Bengali and in a private setting, where the respondents felt comfortable. The interview guideline focused on the history of patient's illness, their experiences with the illnesses, daily life struggles, and the care they receive from the PCAs. The caregiver's experience centred around their support to the ill patients in the light of familial contexts, and the cultural practices. Participants signed the consent forms after a verbal explanation. Interviews were audio-recorded after their approval and took approximately 45 minutes to two hours. Interview notes were recorded on paper forms. Debriefing sessions were conducted after each interview to summarize content and quality of interviews.

\section{Analysis}

The interviews were transcribed in Bangla and were analysed thematically. Initial focus was given on inductive analysis of the data, and identifying the sub-themes arise during analyse the data in the transcripts. A codebook was prepared by discussing the preliminary findings with the research team and validating the coding frame. The transcripts were coded in ATLAS.ti version 8 , and a coding frame was created. Through a constant comparison approach, subthemes were produced and quotations were retrieved from the findings.

\section{Results}

\section{The respondent's}

The respondents migrated in the Korail slum 20-45 years back from their home village. The main reason for migration was to earn a livelihood. All of them were Muslim by religion and the age of the patients ranged from 40-85 years (Table 1, end of the document). Most of them were unemployed, few of them were engaged in shop keeping, rickshaw pulling, boat riding, and begging. Almost all of them lived by the family caregivers and most of the caregivers were female (wife, daughter, daughter in law, nephew wife, sister) and only one was male (husband). The range of the caregivers' age was 25-70 years. Six of them were involved in some sort of work, either small business like owning a street-side shop/tea stall or being a housemaid. 
Table 1

Patient Profile

\begin{tabular}{|lll|}
\hline Gender & Age in range & Suffering duration from disease (in years) \\
\hline M & $55-60$ & 5 \\
\hline F & $75-80$ & 3 \\
\hline M & $65-70$ & 2 \\
\hline F & $35-40$ & 2 \\
\hline M & $75-80$ & 7 \\
\hline F & $55-60$ & 2 \\
\hline M & $65-70$ & 8 \\
\hline F & $55-60$ & 5 \\
\hline M & $60-65$ & 4 \\
\hline F & $60-65$ & 2 \\
\hline
\end{tabular}

\section{Patient's experience and perception of sufferings Physical sufferings}

Most of the patient suffering from their illness for more than 2-8 years. Most of them agonized from various physical conditions such as; weakness, fatigue, nausea, drowsiness, and pain in the body, breathing difficulties, difficulties in sleeping. Majority of them cannot talk for extended period of time, suffers from loss of appetite. Two of them being paralyzed, they can stand but cannot walk. The multitude of different symptoms and suffering made it hard for the patient to live an active and productive life, or even enjoy the family life at their age. Also, they shared their different familial stresses, related to their life, which was hugely affected by the diseases they suffer from. These difficulties caused emotional sufferings which is discussed below.

\section{Emotional sufferings}

Most of the patients were bedridden and dependent on their family members for their daily living and treatment. They not only needed regular medical treatment but also non-medical assistance. Despite the gratefulness, the respondents were carrying enormous guilt because of their dependency on the family for survival. They received physical, emotional, and financial support from the family members whenever needed, but the dependence generated frustration and uncertainty.

It was more painful for male patients, the breadwinner of the family. Instead of taking care of the family, they now require care and support. One of them tearfully expressed; 
'I feel very helpless aunty (addressing the interviewer). My wife is also sick, yet I have to depend on her. She is suffering from a kidney problem. She worked as a maid, do lots of heavy work all day long; I cannot do anything. I cannot earn. Why doesn't Allah take me to him, so I do not suffer anymore?' (Patient_Male_55-60 years old)

\section{Social isolation and loneliness}

Most of the patient felt socially isolated as they were often at home by themselves and felt left out by the family members and friends who worked outside. Most of them shared their helplessness to participate in any social events like festival, marriage ceremony, religious rituals, and any local events. Limited ability to socialize with friends and family made them feel secluded and they suffered from loneliness.

Particularly the male patients felt alone if their wives went to work and there was no other member to spend time with them. One male patient who lost his wife few years back and now lived with his son's family, felt very lonely because he did not receive any support or respect from his son and daughter-inlaw. At the old ages, he still had to make his own living. He said,

'There is no one to take care. My daughter-in-law is busy with household tasks; I can't blame her, she does whatever she can. I sit at a corner all day long. I have to do my own task. I bring my medicine and clothes by myself. There is no one to even cool my head with water if needed" (Patient_Male_65-70 years old)

\section{Financial crises}

Several patients had discontinued institutional treatment due to lack of money. The respondents mentioned that they felt exhausted worrying about their family members without any income source. Some of the patients did not want to work, but they were still involved in income-generating activities for maintaining their families' expenses. One female patient continuing working as a genitor to run her family. Both of her children were suffering from severe diseases (cerebral palsy and visual impairment), and her husband was a disable street beggar. She suffered from anxiety and lost interest towards life.

Few patients (male and female) were also working to earn money and manage household chores. One of the female patients previously sold bread on the street. However, due to their disease condition they were forced to leave their business and could not do the household activities.

"I used to sell bread, during winter I sold "pitha" (a type of cake), and in other seasons I sold bread and fried vegetables. I did very well in the business. I earned a lot of money but now my business is over and the money is finished.'(Patient_Female_60-65 years old)

\section{Caregivers' experience and perception}

The caregivers' experience varied to some extent, as each respondent has his/her struggle in providing care. They were mostly involved with patients during the diagnosis of disease, process of treatment and care provision.

\section{Caregivers' emotional sufferings}


The female caregivers were more actively involved, notably, working female caregivers contributed to the treatment process for both the male and female patients. The financial burden as well as witnessing the pain of their close ones caused emotional stress. The caregiver-respondents were more committed to their patients in the early stage of the disease because they perceived that taking care during the early stage of the disease would prevent further complication and the condition would not deteriorate further. In addition to being the breadwinner of the family, they had to care for the patient that included feeding and bathing, helping them in the toilet and washroom. The only male caregiver mentioned that he assisted his wife in bathing or going to the toilette and or fed her after he came back from his tea shop. Not much time is left for oneself after completion of all the activities and taking care of the patient.

\section{The financial struggle of the caregivers}

Almost all of the caregivers shared that they are in a destitute condition, and are in constant need for money. Those caregivers who are working outside start taking care of their dependents after coming back instead of taking rest. Their daily activities included washing, cleaning, grocery shopping, cooking for the household, filling up the containers of water, and ensuring that all the family members are adequately fed.

"I do the grocery shopping and cleaning. I also have to take care of mother- bathing her, feeding her, grooming her (making hairstyles). Then, there are clothes of the children which need to be washed. All in all, a lot of work. Sometimes I become tired. (CG_Female_25-30 years old)

As almost all of them were impoverished or living on daily wager and this made bearing the cost of treatment even more difficult. Some of them had to spend all their savings for the treatment of their patients and later forced to borrow money. Few of the respondents had taken out loans which they needed to pay back in instalments, an added stress for them. They could not ask for financial help from other extended family members because they also lived on limited income. The caregivers felt helpless because of the uncertainty and suffering of their loved ones. One of the respondents narrated;

"The pain of poverty is massive... If I had property I did not have to ask for money or help to people. If I had money I did not have to go out for work, I could take care of him at home. If I do that now I will have no money to sustain us. I have to work outside, then when I come back home, I have to clean him, feed him... That's why I want that Allah should take me to Him than keep me in this suffering and pain." (CG_Female_45-50 years old)

\section{The feeling of overburden and emotional distress}

Taking care of the patient was an added pressure in their real stressful life. One female respondent felt no one could understand her pain and suffering. Although she suffered and lost a lot, the Almighty who sent her did not ascribe any happiness.

After taking care of the patients for such a long time, all caregivers were habituated with the debilitating condition of the patients. Also, they became frustrated, irritated or disturbed by running the household 
round the clock and taking care of the patients. They had their own responsibilities to fulfil- taking care of the chores, the children, working to earn money so that they can run the household and pay for the treatment- hence, giving the full attention to the patient did not always come naturally. But they also felt the inner conflict within themselves during these moments, as they believed it was their prime duty to take care of their family. Not doing so distressed them emotionally, and they suffered from a guilty conscience.

"How can I not care for her? How can I leave a person by herself in such an ailing condition? It makes me feel guilty (bibeke badha deyi). My husband also asked me to take care of her as she may not have long to live."(CG_Female_20-25 years old)

The only male caregiver shared the same feelings, and opened up about his emotional attachment with his wife as well. He felt exceedingly sad for his wife's ailment as he could not share his life with her anymore. This actually showed how the patient's illness had disrupted the caregiver's life and household.

\section{Double burden of women caregiver}

Women were affected more by the need for care at the end of life. While the male patients received care from their wives despite their wives' own ill health and busy working schedules, the female patients were often deprived of adequate care from their spouses or family members. Moreover, they had to look after the routine household tasks despite their illness. Terminally ill women were also often alone as their husbands had died earlier. We found only one female patient received some assistance from her husband like, buying the medicine but most of the time she had to manage the household and her own needs by herself. She described,

'Whether I am sick or not, I have to do all my household chores. Sometimes I cannot move but have to work. I feel aches but there is no option. I have to take care of my two grandchildren and my husband. But by the grace of God, 'till now I haven't collapsed; in that situation someone will have to take care of me. So far, I can manage everything-I am doing all the chores by myself.'(Patient_Female_55-60 years old)

The responsibility of taking care of the palliative care patients often fell on the females of the household. As six among nine caregivers were working women, it reflected the fact that they maintain the household as well as take care of the palliative care patients. They also mentioned repeatedly that they have to work, otherwise they will not be able to sustain the family, as well as that it becomes a burden that the patient cannot work. Mostly the responsibility of taking care of the patient fell on the wife or the daughter in law of the patient. Sometimes the sister ( 2 among 9 caregivers) of the patient also played the role of caregiver. In only one of the cases, patient's husband took care of her.

\section{Coping with the sufferings by patients and caregivers}

Despite all of the hardships, several patients were still looking forward to a miracle. They were hoping to be cured and living a long life. Respondents who lived with an extended family and had people around to look after them were more optimistic than those who lived with their spouses only. Almost every patient 
expressed their desire to return to their normal and disease-free life when they could earn and were able to do their household chores. They mentioned repeatedly that they missed their earlier active life. The majority of respondents said regular working life, family life, and their life before the illness was the best part of life.

'When my husband was alive, I had my own household (shongshar) that time was the best time in my life. Till now I think about those wonderful days.'(Patient_Female_75-80 years old)

In our study, all the participants were theists and they found peace by practicing their religion. They believed they will be cured if Allah wishes them to be. This belief gave them a comfort and alleviated their sufferings. One patient told,

'I wish Allah will help me to recover soon. I have no regrets. I pray to Allah for my soundness. I do pray every time and seek forgiveness to Allah...Sufferings come from Allah and only he can relive it. So, I do pray all the time for my recovery ....' (Patient_Female_75-80 years old)

Along with praying, many of the patient-respondents mentioned that they felt happiness and peace while playing with their grandchildren.

The patients also spent significant amount of time with the community. Non-bedridden male patients regularly walked to the markets, shops, mosques or chatting neighbours. Almost half of the respondents said that had good relationships with their neighbour's that contributed to a better life. Several respondents explained that their neighbours were friends and male patients spent their leisure time with them.

In case of the caregivers, whatever the condition of the patients, they were optimistic and hopeful about their patients, that one day they would get better and would live a longer life. The situation reminded them about their own fate and health, bringing them close to the realization that this illness could have happened to them as well.

"I feel like crying at times. I don't blame anyone for my misfortune, God has given me this. I console myself saying that this could have happened to me as well. When these thoughts come to my mind, when I talk with people like I am talking with you about these issues, this makes me emotional." (CG_Female_65-70 years old)

And in the end, even though they had to suffer as well with their patient's, they still loved them dearly, and that is what motivated them to keep taking care of the patients.

\section{How the community-based palliative care project 'Momotamoy Korail' supported the urban slum dwellers and their perception towards the Palliative Care Assistants (PCAs)}

Enrolment in 'Momotamoy Korail' programme made the respondents both the patients and their caregivers more confident and contented. They repeatedly recognized the positive effect of the services 
provided by the programme. The respondents were very happy to receive the medicine, advice from the doctor visit, food package and the emotional support from the PCAs. The food packs ensured their food security. They all showed satisfaction with the contribution of the PCAs in their life. The PCAs made the family members, relatives and neighbours of the respondents realize the importance of taking care of the terminally ill or elderly people. The PCAs visited the patients' house, spent time and talked to them and their family. They were providing physical, social, mental and spiritual support to the respondents. As part of physical care, they help the patients doing physical exercise or helping them take a walk who cannot move easily or have severe pain in the body or are physically paralyzed. They often visit patients' house and gave company when they feel lonely or stay alone at home. They help them to take regular medicine doses, to take baths, and sometimes cut their nails too. Sometimes they clean the lonely patients house, make the bed, clean their dishes, do the shopping and cook for them. However, social care is mostly about counselling the family members or relatives of the patient.

Regarding mental support, some of the patients were worried about their impoverished condition. They were stressed and disappointed, witnessing their children's negligence towards them. In such situations the PCAs tried to spend more time with the patients, provide emotional support and instil confidence in them with their positive views toward life.

"Girls wearing blue dress (PCAs) visit our home and care for us. They loved us a lot. We share our problems and thoughts to them. They are like our family. We feel relief to see them" (CG_Female_6065 years old)

All respondents felt grateful to the PCAs. As the PCAs recruited from the community and lives in this community, the patient family knows them and have confidence in them. Whenever the PCAS visit a patient's home, they (patient's family) do not let them leave and if they are late or miss to visit them for any reason the patient gets emotional.

\section{Discussion}

This is the first study that explicitly reveal the contrasting experience of patients with long term illness receiving palliative care and their home care givers in an urban slum in Bangladesh. The patients and caregivers, participated in this study, both described their physical, emotional and financial sufferings due to their condition. In this journey, both express their sympathy and empathy for each other with a colossal toll of anguishes and torments. On the other hand, they also illustrated optimism about life as well particularly for being part of a community based palliative care project.

In the context absence of integrated palliative care in the national health system and of life-threatening poverty situation the terminally ill slum dwellers find their ways to cope with the existing support. The role of a context specific culturally and locally appropriate provision of palliative care service is indisputable. In this case 'Momotamoyee Korail' project plays a pivotal role and the enrolled patients and their families benefited from the project (26) Family care givers are integral part of a community based palliative care, and impart the essential personal care needed in the terminal phase of illness. 
Most of the patients reported partial capacity to join in different social events, not getting chances to socialize with friends and family which makes them feel unaccompanied and lonely. Occasionally their physical limitations and unemployment stimulate the thoughts of feeling abandoned by their family. Perceiving a lack of care and concern from others during illness also contributed to loneliness. Loneliness and isolation has been identified as a common experience of terminally ill patients (27). For wellbeing, social connection to each other is crucial; presence of social association, helps people to be free from loneliness. Theorists have distinguished loneliness as the perception of social isolation and discontent with the quality of relationships (28). The physical changes that the patient undergoes as well as forced limited contact with the other members of the community means that patient does not get the protection against loneliness that the community interaction provides (29).

Findings also elaborated on the fact that the patients think they have become the burden for the family because of their unemployment and inability to take care of themselves. The "self-perceived burden" (SPB) is also a common phenomenon among the terminally ill patients, which is corroborated by other studies. A systematic review done on this aspect of palliative care has shown that SPB is correlated with loss of dignity, suffering and a "bad death" (30). Both male and female patients desire a death free of sufferings and many of them also indicated that they wished they had died earlier. The loneliness, feeling of abandonment, and burden instigate an experience of social death prior to their physical demise (31)

In support of existing literature, the study results also confirmed the central role of women as primary care giver (except only one man) for the palliative care patients. Around the world, women spend two to ten times more time on unpaid care work than men(32). According to the gender norms, women are viewed as being responsible for caregiving tasks and both women and men internalize caring as women's work. Our findings echoed existing literature that female caregivers are more likely to carry out personal care and household tasks than male caregivers (33)

The caregivers are the silent savior (23) but the caring for the sick family members is a duty according to the study participants. According to Mahoney, the Bangla terms for 'duty' is "kartabya" and "daitya", those do not carry the meaning of an abstract obligation, rather the implication is usually about the immediate task at hand or the relational obligation (34). Despite the sense of duty and enormous sympathy and empathy, the care givers of this study felt frustrated and hopeless. They also greatly suffered from common psychological issues among caregivers including depression, hopelessness, anger, as well as sleeplessness. Caring for a terminally ill person at home requires continuous balancing between care burden and capacity to cope (35) particularly in severe financial constraints. Stress was also a common complaint and the caregiver's perceived that the sudden diagnosis of the patient's terminal illness has led them to higher stress. It was found in the study that emotional stress for female caregivers because they had to manage both the patient and other household activities. All the caregivers had this view that women are supposed to be the primary caregivers. However, despite the physical and psychological sufferings, both patients and their caregivers expressed hope about life. They found consolation from the care and support they received from the community based palliative care assistants. 
For caregivers, they often need to reorganize their own lives and lifestyles to suit the patient's needs. This illustrates the fact that the caregiver needs to balance between taking care of the patient and their own capacity to cope with the burden of caring (36). Studies show that caring for a terminally ill person at home may lead to physical and mental fatigue and eventually to burnout if continued without any external support (35). The gender dimension of females being carer for chronic conditions is common in most countries particularly in global South. (37).

Loss of sense of community, loneliness, and lack of collectiveness is broadly a characteristics of Western societies $(38,39)$. However, due to rapid urbanization Bangladesh being a non-Western country also developed the feature of loss of social cohesion (40). This is particularly true for urban slum-like 'Korail', where most of the inhabitants have migrated from different parts of the country to hope for a better livelihood and are involved in some form of income-generating work, including the women in the families (41). It has implications for the end of life care provisions. The community based palliative care project of BSMMU has introduced an innovative way to fill up the gap between individual and the community. The PCAs who are from the same community, play a role in fulfilling the loss of sense of community by sharing the physical, mental, psychological and spiritual care responsibilities along with the family members. Previous studies showed caregivers always add their own experience of suffering and support systems which can influence to their ability to provide care to the patients(42). Our study findings also accumulate with this where it showed, family caregiver dealt with their palliative patient according to their own coping mechanism. Palliative care requires care and support for both health-related and non-healthrelated aspects of life.

However, the support the patients and the caregivers need are far from being adequate. A fraction of the population of Bangladesh receives palliative care, and palliative care provision is still underdeveloped with few isolated initiatives. It is important to mainstream the palliative care in the Bangladesh health system in order to address the physical, psychological, social, emotional, and spiritual sufferings of terminally ill patients which was coined as a term "total pain" (43). In a resource-poor setting like an urban slum, there is a need for innovative approaches for an integrated palliative care service within the main stream health system.

\section{Conclusion}

The experience and perception of the patient and caregivers depend on socio economic status, social network and coping skills depending on the illness status. The suffering, spiritual beliefs, emotional crisis and self-perceived burden intermingle and as a consequence make a complicated scenario even more complex Further study is needed to explore which approaches are most effective to reducing patients' worries and pain about being a burden on their families. Caregivers can provide a major psycho-social support to the patients but it has to be realized that caregivers are exposed to a long-term stress starting from the diagnosis of the patient's illness and continuing even after the death of patient. As such, the caregivers are exposed to higher levels of stress than the patients, which needs to be addressed appropriately. Although studies have been conducted in different countries and context, but the numbers 
are inadequate. To date, there is limited research available in the context of Bangladesh to understand the experience of the palliative care patients and caregivers. The experience of the patients and caregivers demonstrate that further research and effective support for them is much needed. Despite limitations, this study has tried to shed some light on the in the urban slum of Bangladesh in terms of patient and caregiver experience.

\section{Abbreviations}

\begin{tabular}{|ll|}
\hline BRAC JPGSPH & BRAC James P Grant School of Public Health \\
\hline BSMMU & Bangabandhu Sheikh Mujib Medical University \\
\hline CG & Caregiver \\
\hline CKD & Center for Palliative Care \\
\hline IDI & Chronic kidney Disease \\
\hline IRB & In-depth Interview \\
\hline PCA & Institutional Review Board \\
\hline WHO & Palliative Care Assistant \\
\hline WHPCA & World Health Organization \\
\hline
\end{tabular}

\section{Declarations}

\section{Ethics approval and consent to participate}

This study was approved by the Institutional Review Board of the BRAC James P Grant School of Public Health, BRAC University. Interview participants gave their written informed consent for participation and analysis of all collected data.

\section{Consent for publication}

Not Applicable

\section{Availability of data and materials}

The anonymized dataset used during the study are available from the corresponding author on reasonable request.

\section{Competing Interest}

The authors have declared that no competing interests exist 


\section{Source(s) of Funding}

The study was funded by Arts and Humanities Research Council (AHRC), UK.

\section{Authors' contributions}

MS and SZ contributed to the conception and design of the study.SA, PH contributed to the development of the tool.SA organized and led the field activity. MS, SZ, NA assisted with content development, as well as interpreting results. SA, PH drafted the initial version of the manuscript. SZ, NZ, SA and MS reviewed parts of the analysis and reviewed draft articles. All authors edited the manuscript for important content, read, and approved the final manuscript.

\section{Acknowledgement}

This study was coordinated by University of Sussex, UK and funded by Arts and Humanities Research Council (AHRC), UK. We wish to thank all the study interviewed patients and family members who are part of a community based palliative care project facilitated by Bangabandhu Sheikh Mujib Medical University (BSMMU) with a grant by the Worldwide Hospice Palliative Care Alliance (WHPCA). We would also like to thank the dedicated staff of "Momotamoy Korail" for giving us all the necessary support in conducting the research during the period of the study. We also thank two of the Research Assistant (SJM Shourov and Mahabuba Alam Ripa) for their incredible support during data collection for this research.

\section{References}

1. Knaul FM, Farmer PE, Bhadelia A, Berman P, Horton R. Closing the divide: the Harvard Global Equity Initiative-Lancet Commission on global access to pain control and palliative care. Lancet. 2015;386(9995):722-4.

2. Clark D. End-of-life care around the world: achievements to date and challenges remaining. Omega (Westport). 2007;56(1):101-10.

3. Crippen DWe. End-of-Life Communication in the ICU: A Global Perspective. Springer. (2008.

4. Clark D, Graham F. Evolution and change in palliative care around the world. Medicine. 2011;11:6368.

5. WHO. 2014.

6. BRAC. 2014.

7. BRAC. K-. 31 May, 2019.

8. Pastrana T, Vallath N, Mastrojohn J, Namukwaya E, Kumar S, Radbruch L, et al. Disparities in the contribution of low- and middle-income countries to palliative care research. J Pain Symptom Manage. 2010;39(1):54-68.

9. Lynch T, Connor S, Clark D. Mapping levels of palliative care development: a global update. J Pain Symptom Manage. 2013;45(6):1094-106. 
10. Connor SR, Bermedo MC. Global Atlas of Palliative Care at the End of Life. Worldwide Palliative Care Alliance. 2014.

11. Gysels M, Pell C, Straus L, Pool R. End of life care in sub-Saharan Africa: a systematic review of the qualitative literature. BMC Palliat Care. 2011;10:6.

12. Bingley A, Clark D. A comparative review of palliative care development in six countries represented by the Middle East Cancer Consortium (MECC). J Pain Symptom Manage. 2009;37(3):287-96.

13. McDermott E, Selman L, Wright M, Clark D. Hospice and palliative care development in India: a multimethod review of services and experiences. J Pain Symptom Manage. 2008;35(6):583-93.

14. Zaman S, Inbadas H, Whitelaw A, Clark D. Common or multiple futures for end of life care around the world? Ideas from the 'waiting room of history'. Soc Sci Med. 2017;172:72-9.

15. NIPORT. National Situation Analysis of Palliative Care in Bangladesh. 2013.

16. Ventura AD, Burney S, Brooker J, Fletcher J, Ricciardelli L. Home-based palliative care: a systematic literature review of the self-reported unmet needs of patients and carers. Palliat Med. 2014;28(5):391-402.

17. Corrigan JM. Crossing the quality chasm. Building a better delivery system. 2005.

18. Meneguin S, Ribeiro R. Difficulties of caregivers of patients in palliative care in the family health strategy. Text \& Context Texto \& Contexto. 2016;Enfermagem, 25(1.

19. Higginson lea. Social and clinical determinants of preferences and their achievement at the end of life: prospective cohort study of older adults receiving palliative care in three countries. BMC 2017; volume 17:271.

20. Goldstein NE, Concato J, Fried TR, KasI SV, Johnson-Hurzeler R, Bradley EH. Factors associated with caregiver burden among caregivers of terminally ill patients with cancer. J Palliat Care. 2004;20(1):38-43.

21. Harding R, List S, Epiphaniou E, Jones H. How can informal care-givers in cancer and palliative care be supported? An updated systematic literature review of interventions and their effectiveness. Palliat Med. 2011;26(1):7-22.

22. Funk L, Stajduhar K, Toye C, Aoun S, Grande G, Todd C. Part 2: Home-based family caregiving at the end of life: a comprehensive review of published qualitative research (1998-2008). Palliat Med. 2010;24(6):594-607.

23. Zaman S. Silent saviours: family members in a Bangladeshi hospital. Anthropol Med. 2013;20(3):278-87.

24. Knoblauch HS. Focused ethnography. In Forum qualitative sozialforschung/forum:. qualitative social research. 2005;(Vol. 6, No. 3).

25. BRAC. (2014).

26. Zaman S, Ahmed N, Ur Rashid M, Jahan F. Palliative care for slum population: a case from Bangladesh. European Journal of Palliative Care. 2017;24(4):156-60. 
27. Bentley B, De Jong MJ, Moser DK, Peden AR. Factors related to nonadherence to low sodium diet recommendations in heart failure patients. Eur J Cardiovasc Nurs. 2005;4(4):331-6.

28. Cacioppo JT, Hughes ME, Waite LJ, Hawkley LC, Ronald A. Loneliness as a specific risk factor for depressive symptoms: cross-sectional and longitudinal analyses. Psychol Aging. 2006;21(1):140.

29. Sand L, Strang P. Existential loneliness in a palliative home care setting. J Palliat Med. 2006;9(6):1376-87.

30. McPherson CJ, Wilson KG, Murray MA. Feeling like a burden to others: a systematic review focusing on the end of life. Palliat Med. 2007;21(2):115-28.

31. Gaston KJ, Blackburn TM, Greenwood JJ, Gregory RD, Quinn RM, Lawton JH. Abundanceoccupancy relationships. Journal of Applied Ecology. (2000):39-59.

32. Ferrant G, Pesando LM, Nowacka K. Unpaid Care Work: The missing link in the analysis of gender gaps in labour outcomes. Boulogne Billancourt: OECD Development Center; 2014.

33. Miller B, Cafasso L. Gender differences in caregiving: fact or artifact? The Gerontologist. 1992:498507.

34. Mahoney TA, Deckop JR. Evolution of concept and practice in personnel administration/human resource management (PA/HRM). Journal of Management. 1986;12(2):223-41.

35. Proot IM, Abu-Saad HH, Crebolder HF, Goldsteen M, Luker KA, Widdershoven GA. Vulnerability of family caregivers in terminal palliative care at home; balancing between burden and capacity. Scand J Caring Sci. 2003;17(2):113-21.

36. Leroy T, Fournier E, Penel N, Christophe V. Crossed views of burden and emotional distress of cancer patients and family caregivers during palliative care. Psychooncology. 2016;25(11):1278-85.

37. Williams LA, Giddings LS, Bellamy G, Gott M. 'Because it's the wife who has to look after the man': A descriptive qualitative study of older women and the intersection of gender and the provision of family caregiving at the end of life. Palliat Med. 2017;31(3):223-30.

38. Putnam RD. Bowling alone: The collapse and revival of American community. 2000.

39. G. H. Cultural dimensions in management and planning. Asia Pacific Journal of Management. 1984;1(2):81-99.

40. Nilsson J, Rana AK, Kabir ZN. Social capital and quality of life in old age: results from a crosssectional study in rural Bangladesh. J Aging Health. 2006;18(3):419-34.

41. Ishtiaque A, Ullah MS. The influence of factors of migration on the migration status of rural-urban migrants in Dhaka, Bangladesh. Human Geographies. 2013;7(2):45.

42. Siminoff LA, Wilson-Genderson M, Baker S. Depressive symptoms in lung cancer Patients and their family caregivers and the influence of family environment. Psycho-Oncology. 2010;19(12):1285-93. http://doi.org/10.002/pon.696.

43. Mehta C. Understanding of the concept of "Total Pain". Hospice and Palliative Nursing. 2008. 